\title{
USO DA RESTRIÇÃO HÍDRICA NA INOCULAÇÃO DE FUNGOS EM SEMENTES DE ALGODOEIRO (Gossypium hirsutum) ${ }^{1}$
}

\author{
JOSÉ DA CRUZ MACHADO² ; JOÃO ALMIR DE OLIVEIRA ${ }^{3}$; MARIA DAS GRAÇAS G.C.VIEIRA4; \\ MARCELO DE C. ALVES ${ }^{5}$
}

\begin{abstract}
RESUMO - A disponibilidade de sementes com diferentes níveis de infecção por fungos ou outros patógenos transmissíveis por esta via é extremamente importante para diversos estudos em patologia de sementes. A presente pesquisa teve como objetivo avaliar o uso da restrição hídrica na inoculação de sementes de algodoeiro com vistas à obtenção de sementes infectadas por Colletotrichum gossypii, C. gossypii var. cephalosporioides, Botryodiplodia theobromae e Fusarium oxysporum f. sp. vasinfectum. A premissa foi baseada no fato de que infecção de sementes pode ser assegurada e controlada pela manutenção das sementes em contato com a colônia fúngica em desenvolvimento em meio agarizado contendo manitol em potencial osmótico que impeça, temporariamente, a germinação por períodos de incubação mais prolongados. Neste trabalho manitol foi testado nos potenciais hídricos de $0,-0,4,-0,6,-0,8$ e -1,0 $\mathrm{MPa}$. As sementes foram incubadas em câmara de crescimento vegetal a $25^{\circ} \mathrm{C}$, com fotoperíodo de 12 horas, permanecendo nestas condições por tempos variáveis, de acordo com o potencial hídrico utilizado. As sementes foram retiradas do meio e secadas sobre papel de filtro, em condições de laboratório e submetidas aos testes de germinação, emergência em bandejas e sanidade. Pelos resultados, o substrato com potencial hídrico na faixa de $-0,8 \mathrm{a}-1,0 \mathrm{MPa}$, proporcionou condições mais apropriadas para impedir temporariamente a germinação das sementes por um período de 4 e 5 dias, respectivamente, promovendo um maior índice de infecção das sementes, bem como uma maior percentagem de plântulas infectadas.
\end{abstract}

Termos para indexação: infecção de sementes, patologia de sementes, pré-condicionamento de sementes.

\section{USE OF THE WATER RESTRICTION TECHNIQUE IN THE INOCULATION OF FUNGI IN COTTON SEEDS (Gossypium hirsutum)}

\begin{abstract}
Availability of seeds infected by fungi or other transmissible pathogens by this way is extremely important in seed pathology for several purposes. The present research was conducted to evaluate the use of the water restriction technique in the inoculation of cotton seeds in order to obtain seeds infected by Colletotrichum gossypii, Colletotrichum gossypii var. cephalosporioides, Botryodiplodia theobromae and Fusarium oxysporum f. sp. vasinfectum. The premise was based on the fact that seed infection is better ensured and controlled by keeping the seeds in contact with the developing fungal colonies on agar media containing mannitol at osmotic potentials that would arrest seed germination for a longer period of time. In this study mannitol was tested at the potentials of $0,-0.4,-0.6,-0.8 \mathrm{e}-1 \mathrm{MPa}$. Seeds on the fungal colonies were placed in a growth room at $25^{\circ} \mathrm{C}$, with a photoperiod of 12 hours, where they remained for different periods of time, according to the water potential used. After each incubation period seeds were taken out of the media and dried out on paper towels in a lab environment and submitted to the germination, emergence and health tests. Incubation of seeds at water potential ranging from -0.8 to $-1 \mathrm{MPa}$, provided conditions to impede seeds from germinating for a period of up to 4 and 5 days, respectively, and then presenting a greater level of infection and higher percentages of diseased seedlings.
\end{abstract}

Index terms: Seed infection, water restriction, seed pathology, seed pre-conditioning.

\footnotetext{
Submetido em 15/07/2003. Aceito para publicação em 13/01/2004 * Trabalho conduzido com apoio da FAPEMIG/ CNPq

${ }^{2}$ Ph.D, Professor, Dep. Fitopatologia/UFLA, cx..P. 37, Cep 37200000, LavrasMG, machado@ufla.br

${ }^{3}$ Dr. Professor, Dep. Agricultura/UFLA, cx..P. 37, Cep 37200000, LavrasMG, jalmir@ufla.br
}

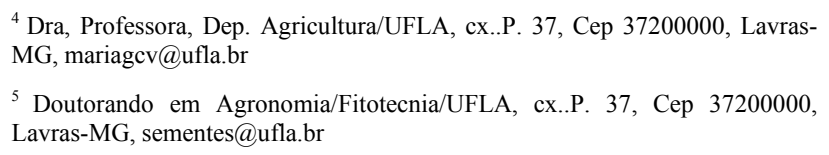

${ }^{4}$ Dra, Professora, Dep. Agricultura/UFLA, cx..P. 37, Cep 37200000, LavrasMG, mariagcv@ufla.br

${ }^{5}$ Doutorando em Agronomia/Fitotecnia/UFLA, cx..P. 37, Cep 37200000, Lavras-MG, sementes@ufla.br 


\section{INTRODUÇÃO}

A cultura do algodoeiro está sujeita à incidência de um elevado número de doenças, cujos patógenos são, em sua maioria, transportados e/ou transmitidos por sementes. Por meio dessa via inúmeras doenças podem ser disseminadas a longas distancias e causar prejuízos dos mais elevados dependendo das condições de ambiente e outros fatores que favorecem o seu desenvolvimento. Estudos no âmbito de sanidade de sementes requerem em geral a disponibilidade de sementes portadoras dos patógenos alvos em quantidade e qualidade adequadas para cada objetivo específico, como tratamento de sementes, aspectos epidemiológicos, desenvolvimento de métodos de detecção etc. (Machado, 2000; Carvalho, 1999)

A inoculação de sementes com patógenos, na maioria fungos, para diversos estudos, tem sido tradicionalmente realizada por meio da embebição das sementes em suspensão de inóculo, como conídios. Por esta metodologia o processo de infecção não é, entretanto assegurado a priori e sim contaminação superficial, (Costa et al. 2003).

A inoculação de plantas adultas visando à obtenção de sementes infectadas é uma forma ainda bastante considerada no âmbito da fitopatologia porém apresenta também inconvenientes como o longo período de tempo requerido para o cultivo das plantas indo até a colheita. De acordo com Neergaard, 1979; Machado 1994 e Menten, 1988, a utilização desse procedimento, além da demora envolvida na sua execução, é também de eficácia questionável, pois a transmissão de patógenos da planta para a semente constitui um processo dinâmico, que depende de vários fatores inerentes ao patógeno, ao hospedeiro e ao meio ambiente e estes fatores nem sempre são passíveis de controle operacional.

Exemplo de inoculação de plantas para obtenção de sementes infectadas é apresentado por Tanaka e Menten, 1992, por meio da aplicação de suspensão de conídios de Colletotrichum gossypii var. cephalosporioides, em diferentes cultivares de algodão, no estádio fenológico de maçãs formadas. Por esta metodologia foi possível obter índices de $1,5 \%$ a $11,5 \%$ de ocorrência do referido fungo nas sementes produzidas, e quando estas sementes foram plantadas, proporcionaram de $1 \%$ a $6,5 \%$ de plântulas com sintomas de ramulose. Uma forma alternativa de inoculação visando obter sementes de feijão infectadas por Colletotrichum lindemuthianum, causador da antracnose, foi desenvolvida por pesquisadores da Universidade Federal de Lavras (Carvalho, 1999), lançando-se mão do pré-condicionamento osmótico das sementes.

Diante das dificuldades de se dispor de sementes de algodão infectadas por diferentes patógenos como Colletotrichum gossypii, Colletotrichum gossypii var. cephalosporioides, Botryodiplodia theobromae e Fusarium oxysporum f. sp. vasinfectum, é que se propôs este trabalho, tendo como alvo central desenvolver um procedimento de inoculação das sementes por meio da técnica de restrição hídrica, capaz de proporcionar elevados índices de infecção pelos referidos patógenos.

\section{MATERIAL E MÉTODOS}

O experimento foi conduzido no Laboratório de Patologia de Sementes do Departamento de Fitopatologia da Universidade Federal de Lavras - MG, no ano de 2000.

As sementes utilizadas, da cultivar IAC-20 e deslintadas foram inicialmente desinfestadas com solução de hipoclorito de sódio a $1 \%$ por 1 minuto, e daí lavadas com água corrente e secadas à sombra. Em seguida foram submetidas aos testes de germinação e sanidade para avaliação de sua qualidade.

Os fungos utilizados no presente trabalho, foram isolados de sementes de algodoeiro, em análises de rotina realizadas no Laboratório de Patologia de Sementes da UFLA. O meio de cultura básico utilizado na inoculação foi BDA (extrato de $200 \mathrm{~g}$ de batata, $20 \mathrm{~g}$ de dextrose e $20 \mathrm{~g}$ de ágar), ao qual foi adicionado o soluto manitol nos potenciais hídricos $0,-0,4,-0,6,-0,8$ e -1,0 MPa. As concentrações para o preparo dos meios, em cada potencial hídrico foram obtidas por meio da fórmula proposta por Van't Hoff (Salisbury e Ross, 1991).

Após a autoclavagem, o meio de cultura contendo manitol, foi vertido em placas de petri de $15 \mathrm{~cm}$ de diâmetro, $50 \mathrm{ml}$ de meio por placa, sendo utilizadas cinco placas para cada concentração do restritor. Três discos de Agar, $5 \mathrm{~mm}$ de diâmetro, repicados da colônia pura de cada fungo foram transferidos, em separado, para cada placa e estas incubadas em câmara com fotoperíodo de $12 \mathrm{~h}$ e temperatura de $25^{\circ} \mathrm{C}$ por cinco dias. Em seguida, $40 \mathrm{~g}$ de sementes foram distribuídas sobre a colônia de cada fungo em camada única e levemente prensadas sobre o meio, permanecendo nos substratos em diferentes períodos de exposição em função do potencial hídrico do substrato. No momento em que qualquer das sementes apresentava início de protrusão radicular as sementes eram removidas do meio e colocadas a secar sobre papel-de-filtro em condições de laboratório. Os tempos de retirada das sementes foram 48 horas para os potenciais de 0,0 e $-0,4 \mathrm{MPa}$ e de 72,96 e 120 horas para os respectivos potenciais hídricos de $-0,6 ;-0,8 ;-1,0 \mathrm{MPa}$. As sementes após a secagem foram submetidas aos testes de: germinação, emergência em solo e sanidade. Estes testes foram conduzidos conforme a seguinte descrição:

Teste de Germinação - Conduzido com quatro repetições de 50 sementes por tratamento, em substrato de papel-toalha, umedecido com água destilada 2,5 vezes o peso do papel no sistema de rolos. Após a montagem dos rolos, estes foram levados para um germinador, à temperatura de aproximadamente $25^{\circ} \mathrm{C}$, onde permaneceram por sete dias. $\mathrm{Na}$ avaliação, foram computadas porcentagens de plântulas normais, anormais e sementes mortas, segundo Brasil, 1992. 
Teste de emergência em solo - Foi realizado em bandejas plásticas contendo areia e solo misturados na proporção de 2:1. Foram utilizadas quatro repetições de 50 sementes por tratamento, semeadas na profundidade de 1,5 $\mathrm{cm}$. Após a semeadura, as bandejas foram distribuídas ao acaso em sala de crescimento vegetal, com temperatura de $25^{\circ} \mathrm{C}$ e fotoperíodo de 12 horas. A irrigação do substrato foi realizada de dois em dois dias, com volumes iguais de água para cada bandeja. As avaliações foram realizadas, aos sete e vinte e um dias após a semeadura, computando-se o número de plântulas normais. Após 21 dias as plântulas foram removidas e analisadas quanto à presença de sintomas da doença causada pelos patógenos em estudo.

Teste de Sanidade - Realizado pelo método de Incubação em Substrato de Papel, testando sementes, em número de 200 ( 8 repetições de 25 sementes por placa de 15 $\mathrm{cm}$ de diâmetro), desinfestadas com solução de hipoclorito de sódio $1 \%$ por um minuto e não desinfestadas. As placas foram mantidas em câmara de incubação à $22^{\circ} \mathrm{C}$ em regime alternado de 12 horas de luz e 12 horas de escuro. Aos sete dias após a semeadura procedeu se à avaliação do teste por meio de observação da presença de cada fungo nas sementes com auxílio de um microscópio estereoscópico.

Crescimento micelial em meio de cultura osmoticamente modificado- Os efeitos da restrição hídrica no crescimento micelial dos fungos foram avaliados por meio de cultivos em meio BDA (extrato de batata dextrose - ágar), ao qual foi adicionado o soluto manitol nos potenciais hídricos $0,-0,4,-0,6,-0,8$ e -1,0 MPa. Após a adição do manitol em cada concentração, o meio foi autoclavado e $20 \mathrm{ml}$ foram vertidos em placas de Petri de $9 \mathrm{~cm}$ de diâmetro. Discos de agar de $5 \mathrm{~mm}$ de diâmetro foram retirados da periferia das colônias de cada fungo e transferidos para o centro de cada placa, sendo utilizadas cinco placas por fungo e concentração de manitol. As placas foram vedadas com rolopac e distribuídas ao acaso em câmara de incubação, com fotoperíodo de 12 horas, e temperatura de $25^{\circ} \mathrm{C}$.

As avaliações foram realizadas diariamente, medindo na base de cada placa o diâmetro da colônia de cada fungo até a ocupação completa da placa. O índice de crescimento micelial (ICM) foi determinado pela fórmula proposta por Oliveira, 1991:

$$
I C M=\frac{C_{1}}{N_{1}}+\frac{C_{2}}{N_{2}}+\ldots+\frac{C_{n}}{N_{n}}, \text { sendo: }
$$

$\mathrm{ICM}=$ Índice de crescimento micelial

$\mathrm{C} 1, \mathrm{C} 2, \mathrm{Cn}=$ Crescimento micelial das colônias na primeira, segunda e última avaliação

$\mathrm{N} 1, \mathrm{~N} 2, \mathrm{Nn}=$ Número de dias

A análise estatística foi realizada com o auxílio do procedimento ANOVA do SAS (SAS Institute Inc. 1995).
O delineamento experimental utilizado nos ensaios foi o inteiramente casualisado. As médias foram comparadas pelo teste de Tukey, analisando cada potencial como uma metodologia isolada (variável qualitativa).

\section{RESULTADOS E DISCUSSÃO}

Com base nos resultados do teste de germinação (Figura 1), ficou evidenciado que para Colletotrichum gossypii e Colletotrichum gossypii var. cephalosporioides o aumento do potencial hídrico do meio promoveu uma redução gradual no percentual de germinação e um aumento conseqüente do percentual de sementes mortas. No tratamento em que não houve restrição hídrica, o percentual de plântulas com lesões características desses patógenos foi elevado. De posse desses resultados verifica-se que o tempo de exposição das sementes a estes fungos não precisa ser prolongado além de 48 horas, pela rapidez de seu crescimento. $\mathrm{O}$ maior índice de plântulas infectadas pelos referidos fungos ocorreu no potencial -0,6 $\mathrm{MPa}$; nos potenciais acima desta concentração, os fungos provocaram a morte das sementes, provavelmente como conseqüência do maior nível de potencial de inóculo determinado pelo maior tempo de exposição das sementes aos patógenos.

Para o caso de Botryodiplodia theobromae (Figura 1), verificou-se que no menor tempo de exposição, mais de $80 \%$ das sementes foram mortas, e nas concentrações acima de $-0,6 \mathrm{MPa}$ a taxa de mortalidade foi de $100 \%$. Estes resultados confirmam informações de Oliveira (1994), cujos estudos revelaram que o referido fungo é altamente patogênico ao algodoeiro, causando a morte das sementes e promovendo também o tombamento das plântulas recém germinadas.

Por sua vez Fusarium oxysporum f. sp. vasinfectum, provocou um aumento no percentual de plântulas com lesões e de sementes mortas, à medida que se aumentou o potencial hídrico do meio. As sementes que ficaram em contato com o fungo nos potenciais de $0,-0,4$ e - $-0,6 \mathrm{MPa}$ de manitol, não diferiram da testemunha, tratamento sem inoculo, quanto à percentagem de germinação. Na concentração de $-0,6 \mathrm{MPa}$, cerca de $60 \%$ de plântulas estavam infectadas e a germinação próxima de $80 \%$.

Pelo teste de emergência das plântulas em solo / areia (Figura 2). Observa-se que nas sementes inoculadas com Colletotrichum gossypii, os estandes aos 7 dias após a semeadura foram reduzidos nos tratamentos em que a restrição hídrica era de -0,8 e -1,0 MPa, quando comparados com a testemunha. Já com relação ao estande e plântulas com lesões aos 21 dias, não houve diferenças significativas entre as diferentes concentrações. Independente da concentração o estande foi acentuadamente reduzido quando comparado com os resultados das sementes não inoculadas. 

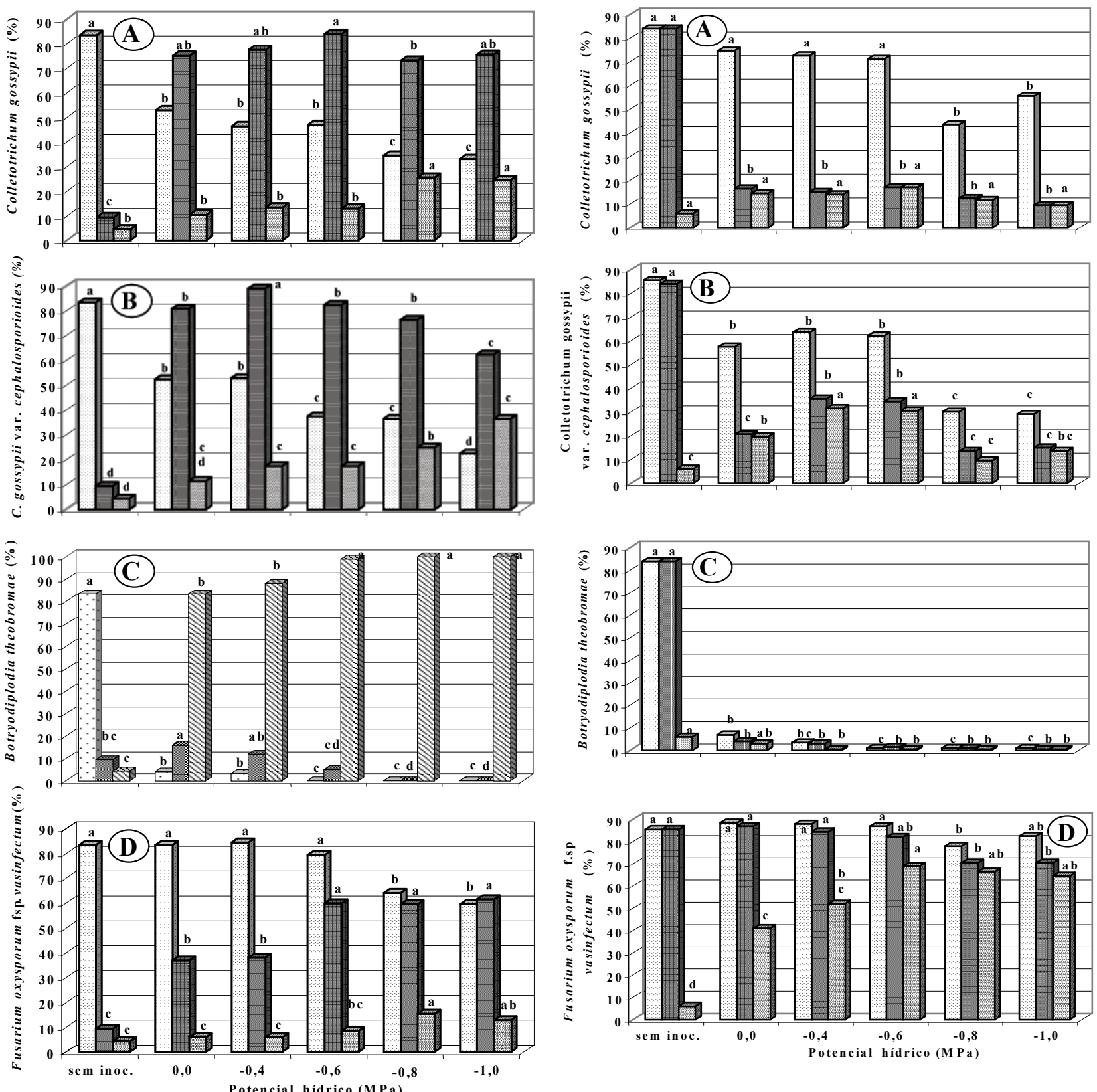

FIGURA 1. Valores médios (\%) de germinação ( $\square$ ), plântulas com lesões ( $\square)$ e sementes mortas ( $\square$ ) do teste de germinação em sementes de algodão, inoculadas com Colletotrichum gossypii (A), Colletotrichum gossypii var. cephalosporioides (B), Botryodiplodia theobromae (C) e Fusarium oxysporum f. sp. vasinfectum (D), em diferentes potenciais hídricos. Médias seguidas pela mesma letra, para cada parâmetro, não diferem entre si pelo teste de Tukey a $5 \%$.

FIGURA 2. Valores médios (\%) de plântulas normais aos sete ( $\square$ ) e 21 ( $\square$ ) dias e plântulas com lesões ( $\square$ ) do teste de emergência em sementes de algodão, inoculadas com Colletotrichum gossypii (A), Colletotrichum gossypii var. cephalosporioides (B), Botryodiplodia theobromae (C) e Fusarium oxysporum f. sp. vasinfectum (D), em diferentes potenciais hídricos. Médias seguidas pela mesma letra, para cada parâmetro, não diferem entre si pelo teste de Tukey a $5 \%$. 
Os valores de estande em relação a $C$. gossypii var. cephalosporióides, foram semelhantes aos resultados observados para o agente da antracnose, porém um pouco menores. Nos menores potenciais hídricos houve redução do estande aos 7 dias e aos 21 dias após semeadura, tanto o estande como o percentual de plântulas com lesões foram acentuadamente reduzidos. Pelos altos percentuais de plântulas com lesões demonstradas pelo teste de germinação em laboratório, e pela agressividade comprovada, pode-se explicar o baixo percentual de plântulas normais obtidas aos 21 dias.

Os resultados do teste de emergência de plântulas oriundas das sementes inoculadas com Botryodiplodia theobromae, foram semelhantes àqueles obtidos pelo teste de germinação (Figura 1), onde esse fungo foi altamente patogênico provocando a morte das sementes mesmo no menor tempo de exposição, 48 horas, para os potenciais de 0 e -0,4 MPa. Já para as sementes que foram inoculadas com Fusarium oxysporum f.sp. vasinfectum, observa-se que, nos potenciais de $0,-0,4$ e $-0,6 \mathrm{MPa}$ não houve diferenças significativas com relação ao estande aos 7 e 21 dias, quando comparados com os resultados das sementes que não foram inoculadas. No entanto nos potenciais de 0,8 e $-1,0 \mathrm{MPa}$, houve uma pequena redução no estande. Observou-se ainda (Figura 1) que o percentual de plântulas com lesões características deste fungo foi superior nos potenciais de $-0,6,-0,8$ e -1,0 Mpa.

Pelos resultados do teste de sanidade para todos os fungos estudados (Figura 3), foi possível perceber que o inóculo de todos penetrou nas sementes em todos os potenciais hídricos, provocando infecção.

Nota-se que não houve grandes diferenças na percentagem de ocorrência dos fungos entre as sementes desinfestadas e não desinfestadas o que reforça a elevada eficácia da técnica de restrição hídrica em infectar as sementes nesta interação biológica. Ressalta-se porém que as sementes que foram inoculadas em substrato sem restrição hídrica apresentaram um índice elevado de infecção, conforme ficou evidenciado pelo percentual de plântulas com lesões no teste de germinação (Figura 1), bem como o baixo percentual de plântulas estabelecidas pelo teste de emergência (Figura 2).

Pelos resultados de crescimento micelial dos fungos em estudo, em meio BDA modificado osmoticamente, o crescimento de Botryodiplodia theobromae e Colletotrichum gossypii não foi prejudicado pelos diferentes potenciais hídricos utilizados. Fusarium oxysporum f. sp. vasinfectum foi estimulado, visto que, no meio sem restrição hídrica, o índice do crescimento micelial foi menor que nos demais potenciais. Este comportamento também foi verificado para o fungo Colletotrichum gossypii var. cephalosporoides, nas concentrações mais baixas de manitol (- 0,4 e-0,6 MPa).
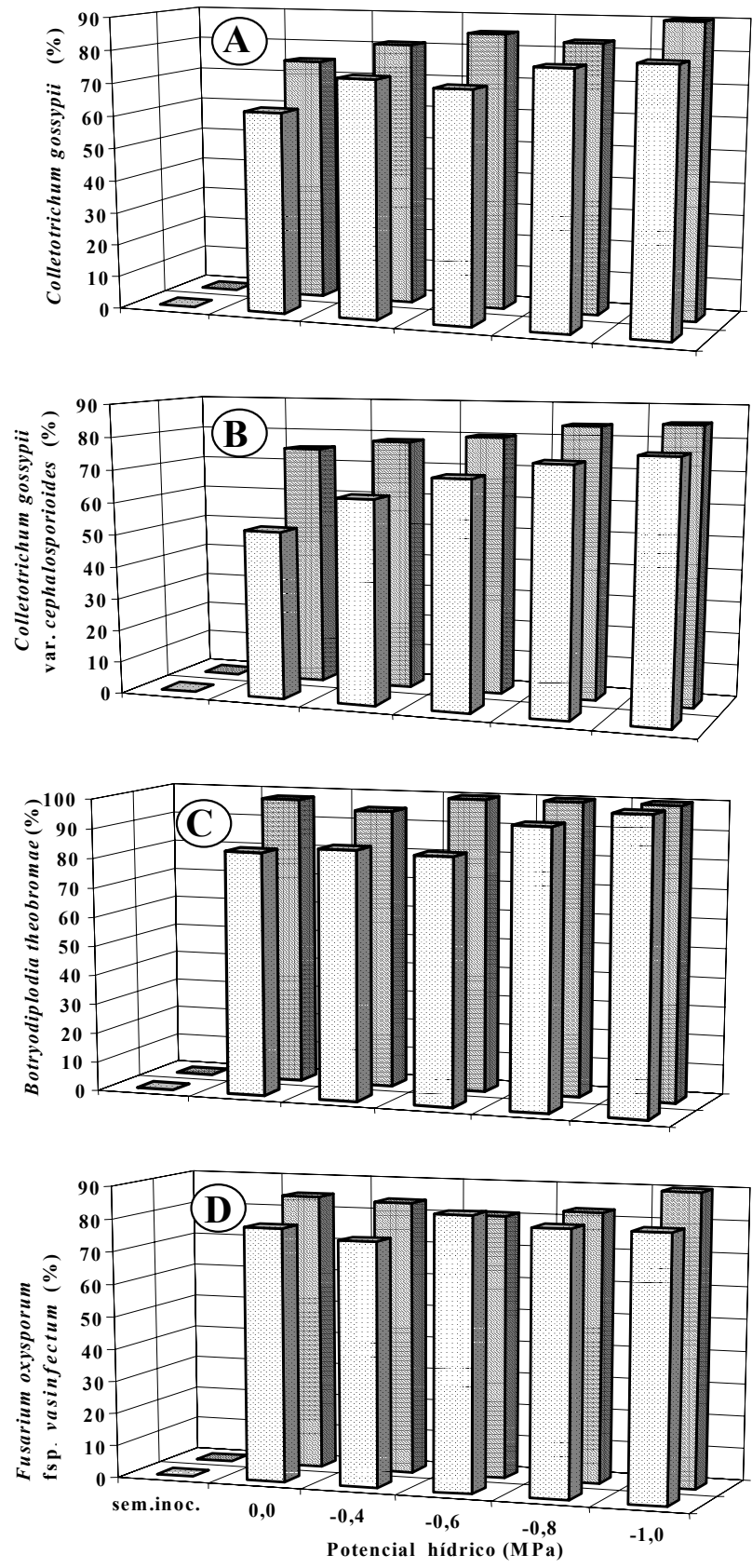

FIGURA.3. Porcentagens de Colletotrichum gossypii (A), Colletotrichum gossypii var. cephalosporioides (B), Botryodiplodia theobromae (C) e Fusarium oxysporum fsp. vasinfectum (D), detectadas pelo teste de sanidade "Incubação em Papel-de-Filtro", em sementes de algodão, com e sem inoculação em diferentes potenciais hídricos e desinfestadas ( $\square$ ) e não desinfestadas ( $\square$ ) com hipoclorito de sódio a $1 \%$. 
A utilização da restrição hídrica como meio de se obter sementes infectadas apresenta vantagens sobre outros métodos por não depender de aspectos como sazonalidade e de operações morosas que nem sempre proporcionam resultados satisfatórios. Conforme demonstrado no presente caso, o nível de penetração ou colonização do patógeno nas sementes pode ser controlado de acordo com o período de exposição das sementes ao fungo. Em outros métodos o nível diferenciado de infecção dificilmente é alcançado.

\section{CONCLUSÕES}

O pré-condicionamento de sementes de algodão utilizando manitol como restritor hídrico, revela ser um procedimento altamente eficaz para obtenção de sementes infectadas por importantes fungos a esta cultura como: Botryodiplodia theobromae, Colletotrichum gossypii, Colletotrichum gossypii var. cephalosporioides e Fusarium oxysporum f. sp. vasinfectum,

Em substratos de cultivo fúngico contendo manitol em potencias hídricos de $-0,4,-0,6,-0.8,-1,0 \mathrm{MPa}$, o crescimento micelial dos fungos em estudo não é prejudicado.

O aumento do potencial hídrico até o nível de $-1,0$ $\mathrm{MPa}$ (potencial máximo testado neste trabalho) proporciona maiores índices de infecção das sementes de algodão pelos fungos testados sem inviabilizar as sementes para usos posteriores.

\section{REFERÊNCIAS}

BRASIL. Ministério da Agricultura e Reforma Agrária. Regras para análise de sementes. Brasília: SNDA/DNDV/CLAV, 1992. 365p.

CARVALHO, J. C. B. Uso da restrição hídrica na inoculação de Colletotrichum lindemuthianum em sementes de feijoeiro (Phaseolus vulgaris L. ). Lavras. 1999. 98f. Dissertação (Mestrado em Fitopatologia). Universidade Federal de Lavras, 1999.

COSTA, M.L.N.; MACHADO, J.C.; GUIMARÃES, R.M.; POZZA, E.A.; ORILE, D. Inoculação de Fusarium oxysporum f.sp. phaseolis em sementes de algodoeiro através de restrição hídrica. Ciência and Agrotecnologia, Lavras,v.27,n.5, p.1023-1030, 2003.

MACHADO, J.C. Tratamento de sementes no controle de doenças. Lavras: Editora UFLA, 2000, 138 p.

MACHADO J.C. Padrões de tolerância de patógenos associados às sementes. In: LUZ, W. C. (Ed.). Revisão anual de patologia de plantas, Passo Fundo, 1994, v. 2, p. 239-236,

MACHADO, J.C. Patologia de sementes: fundamentos e aplicações. Brasília: Ministério da Educação, ESALFAEPE, 1988. 107p.

MENTEN, J. O. M. Semana de atualização em patologia de sementes. Piracicaba: FEALQ/ESALQ, 1988. 76p.

NEERGAARD. P. Seed pathology. London: MacMillan Press. 1979. 838p.

OLIVEIRA, J. A . Efeito do tratamento fungicida em sementes e no controle de tombamento de plântula de pepino (Cucumis sativus L.) e pimentão (Capsicum annuum L.). Lavras. 1991. 111f. Dissertação (Mestrado em Agronomia). Universidade Federal de Lavras, 1991.

OLIVEIRA, E. de. Aspectos patológicos de Botryodiplodia theobromae pat. em relação a sementes de algodoeiro (Gossypium hirsutum L.). Lavras. 1994. $127 \mathrm{f}$. Tese (Doutorado em Agronomia). Universidade Federal de Lavras, 1994.

SALISBURY, F. B.:ROSS, C. W. Plant physiology. 4 ed., Belmont: Wadsworth, 1991. 682p.

SAS Institute. SAS language and procedures: Usage. Version 6. Cary NC: SAS Institute,1995. 373p.

TANAKA, M. A. S.; MENTEM, J. O. M. Relação entre a resistência do algodoeiro à ramulose e a transmissão de Colletotrichum gossypii var. cephalosporioides pelas sementes. Summa Phytopathologica, Piracicaba, v.18, n.3/4, p.227-234, 1992.

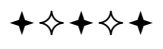

